Int. J. Electrochem. Sci., 11 (2016) $7976-7989$

International Journal of

ELECTROCHEMICAL

SCIENCE

www.electrochemsci.org

\title{
QCM Humidity Sensors Based on Organic/Inorganic Nanocomposites of Water Soluble-Conductive Poly(diphenylamine sulfonic acid)
}

\author{
Şule Dinç Zor ${ }^{*}$, Hüsnü Cankurtaran \\ Y1ld1z Technical University, Faculty of Science and Arts, Department of Chemistry, \\ 34220 Davutpaşa-Istanbul, Turkey \\ *E-mail: sule_dinc@yahoo.com
}

doi: $10.20964 / 2016.09 .51$

Received: 14 June 2016 / Accepted: 12 July 2016 / Published: 7 August 2016

This paper describes the detection of relative humidity $(\mathrm{RH})$ through measurements of the resonance frequency of the quartz crystal microbalance (QCM) electrodes coated with the novel organic/inorganic hybrid composites of poly (diphenylamine sulfonic acid) (EPSDA), 3mercaptopropyltrimethoxysilane (MPTMS) and nano- $\mathrm{Al}_{2} \mathrm{O}_{3}$ powder. EPSDA was synthesized by constant potential electrolysis of diphenylamine sulfonic acid on $\mathrm{Pt}$ sheet electrode in $\mathrm{HCl}$ media at 0.8 V. The different composite mixtures were simply prepared by ultrasonication of acidic aqueous solution of EPSDA with MPTMS and with or without nano- $\mathrm{Al}_{2} \mathrm{O}_{3}$. As prepared sol-gels were drop casted onto the quartz electrodes, and then dried to obtain sensing films. The measured frequency shifts under exposure of different humidity levels showed that the whole sensors studied have high sensitivity, durability and repeatability, almost a full range of linear relative humidity response, fast response/recovery times and low hysteresis. Moreover, they have high selectivity towards humidity over the various polar and non-polar solvent vapors such as alcohol, ketone, ester, chlorinated and nonchlorinated hydrocarbons. These results promise that the EPSDA based organic-inorganic hybrid composites have superior properties for relative humidity measurements.

Keywords: Humidity sensor, quartz crystal microbalance, poly(diphenylamine sulfonic acid), organic/inorganic hybride composites, nanocomposite sensor.

\section{$\underline{\text { FULL TEXT }}$}

(C) 2016 The Authors. Published by ESG (www.electrochemsci.org). This article is an open access article distributed under the terms and conditions of the Creative Commons Attribution license (http://creativecommons.org/licenses/by/4.0/). 